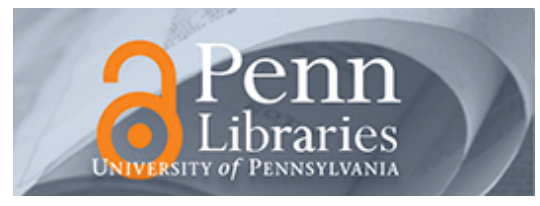

University of Pennsylvania

ScholarlyCommons

Marketing Papers

Wharton Faculty Research

2002

\title{
The Inter-Store Mobility of Supermarket Shoppers
}

Hongjai Rhee

David R. Bell

University of Pennsylvania

Follow this and additional works at: https://repository.upenn.edu/marketing_papers

Part of the Advertising and Promotion Management Commons, Applied Behavior Analysis Commons, Behavioral Economics Commons, Business Administration, Management, and Operations Commons, Cognition and Perception Commons, Cognitive Psychology Commons, Marketing Commons, Organizational Behavior and Theory Commons, and the Sales and Merchandising Commons

\section{Recommended Citation}

Rhee, H., \& Bell, D. R. (2002). The Inter-Store Mobility of Supermarket Shoppers. Journal of Retailing, 78 (4), 225-237. http://dx.doi.org/10.1016/S0022-4359(02)00099-4

This paper is posted at ScholarlyCommons. https://repository.upenn.edu/marketing_papers/270

For more information, please contact repository@pobox.upenn.edu. 


\title{
The Inter-Store Mobility of Supermarket Shoppers
}

\begin{abstract}
The allegiance of a particular customer, and the distribution across customers of strength of affiliation to a store are important indicators of store health. It is therefore important to understand the extent and determinants of shopper mobility among competing retailers. While shoppers often patronize many stores, they typically have a primary affiliation to a "main store" that captures the majority of their purchases. We examine, in detail, the tendencies of shoppers to transition away from the current main store and adopt another in its place. That is, rather than study all types of store switching behavior, we focus on the decision to change primary allegiance. The model is established in a discrete time hazard framework and estimated as random-effects probit. Data from 548 households taking 88,945 shopping trips among five stores are used to calibrate the model. We find that state dependence is prevalent with nearly three quarters of the shoppers showing progressive attachment to their current main store. Interestingly, this finding is not simply driven by location (i.e., because shoppers are captive to a single store based on geographical distance). More likely, shoppers are unwilling to give up the benefits of storespecific knowledge of assortment, layout and prices. Second, the decision to transition from a current main store is not influenced by temporary price promotions on a common basket of items: Shoppers will cherry-pick, but this alone does not cause them to change primary allegiance. The majority of transitions occur across competing stores of the same price format, which suggests "format loyalty" is an important aspect of shopper behavior. After controlling for unobserved heterogeneity, we find little relationship between observable demographics and the transition probability. We do, however, find that shoppers who spend more per trip are less likely to change main stores, as are less frequent shoppers. Implications for retail management strategy are discussed.
\end{abstract}

\section{Keywords}

shopping behavior, retail competition, store loyalty

\section{Disciplines}

Advertising and Promotion Management | Applied Behavior Analysis | Behavioral Economics | Business | Business Administration, Management, and Operations | Cognition and Perception | Cognitive Psychology | Marketing | Organizational Behavior and Theory | Sales and Merchandising 


\title{
The Inter-Store Mobility of Supermarket Shoppers
}

\author{
Hongjai Rhee
}

David R. Bell ${ }^{1}$

November 14, 2001

\footnotetext{
${ }^{1}$ Hongjai Rhee is an Analyst at the Korea Information Society Development Institute, 1-1 Juamdong, Kwa-Chun, Korea 427-070. Email: hrhee@sunnet.kisdi.re.kr. David R. Bell is Associate Professor, Wharton School, University of Pennsylvania, 1400 SH-DH, Philadelphia 19104. Email: davidb@marketing.wharton.upenn.edu. The authors are very grateful to Doug Honnold, IRI Inc., for providing the data used in this study and to Keisuke Hirano and Christophe Van den Bulte for comments. We greatly appreciate the suggestions of the Editors and three anonymous reviewers on an earlier draft.
} 


\title{
The Inter-Store Mobility of Supermarket Shoppers
}

\begin{abstract}
The allegiance of a particular customer, and the distribution across customers of strength of affiliation to a store are important indicators of store health. It is therefore important to understand both the extent and determinants of consumer mobility across competing retailers. We assume that while shoppers may patronize many stores, they typically have a primary affiliation to a "main store." To understand mobility, we model the tendencies of shoppers to transition away from this main store and adopt another in its place. The model is formulated as a random-effects probit and includes shopper, store and time-specific covariates. Data from 548 households taking 88,945 shopping trips among five stores are used to calibrate the model.

The substantive findings are as follows. First, we find that inertia is prevalent (nearly three quarters of the consumers show progressive attachment to a main store). Interestingly, this finding is not simply driven by location because shoppers are captive to a single store based on geographical distance. It more likely reflects the benefits of store-specific knowledge of assortment, layout and prices. Second, the decision to transition from a main store is not influenced by temporary price promotions on a common basket of items: shoppers will cherry pick, but this alone does not cause them to change allegiance. Moreover, the majority of transitions occur across competing stores of the same price format suggesting that "format loyalty" is an important aspect of shopper behavior. Third, after controlling for unobserved heterogeneity, we find little relationship between observable demographics and the transition probability - this result is counter to that for store choice behavior. We do, however, find a significant link between the shopping behavior profile and the associated transition probability: shoppers who spend more per trip are more inertial as are less frequent shoppers. Fourth, shoppers are highly inertial - the longer they remain with a preferred main store, the more likely it is they will continue to do so. Implications for retail management strategy are discussed.
\end{abstract}

KEy Words: Shopping Behavior, Retail Competition, Mobility, Random Effects. 


\section{Introduction}

Retailers seek to strike a balance between acquiring new customers (newcomers to the market), stealing competitors' customers and retaining existing customers. The success of a store hinges on its ability to protect existing customers from turnover, and at the same time to attract more outside customers. In this paper we study the extent and determinants of shopper mobility among stores.

Our work is in the tradition of recent studies of store switching behavior and choice dynamics (e.g., Popkowski Leszczyc et al 1996; 2000) and shares some conceptual similarities with studies in labor economics (e.g., Blumen et al 1955; Farber 1994). In this literature, choice decisions are analyzed as if they comprise a "process" of movement between types of employment and this is reflected in the probability that an individual in a particular line of employment will transition out to another career. We focus on the likelihood that a shopper with a strong allegiance to a particular retailer will transition to a competitor as their preferred destination.

The notion of transition is conceptually useful in the study of mobility and customer management. First, the store choice decision is likely to involve a reasonable degree of cognitive effort - particularly in relation to the effort expended on brand choice decisions. Trips to stores involve time and financial outlay and in addition, place natural constraints on the product and price assortment the consumer will encounter. One might therefore expect shoppers to deliberate carefully before developing allegiances, and having done so, remain somewhat faithful.

Second, consumers appear to habituate to store environments over time. Bell et al (1998) report that for most shoppers, consideration sets for stores are relatively small. Furthermore, shoppers derive benefits from the accumulation of store-specific knowledge and are in effect willing to pay higher prices to shop in stores that they know well. A reevaluation of the preferred store may only occur when the shopper perceives a substantial change in the mar-

keting environment. Alternatively, some shoppers may be cherry pickers or variety seekers by 
nature (e.g., Trivedi et al 1994; Lal and Rao 1997). Positive state dependence, or consumer inertia, has been the focus of previous work on brand switching and brand choice (e.g., Gonul and Srinivasan (1993); Trivedi et al. 1994; Keane 1997; Chintagunta 1998; Seethuraman et al 1999) but has yet to be fully explored within the context of store selection decisions.

Third, from a retail management point of view, it may be more instructive to consider the time series of customer selection decisions as indicative of relationships with a stores, rather than as simply a collection of independent choices and transactions. In sum, the task of the retail manager is to focus on retaining the existing customers while trying to capture new customers (either new entrants or shoppers loyal to competitors). To help the retail manager discern the nature of this task, we address the following questions:

1. What is the extent of mobility? Are shoppers inertial in store choices? If so, do they exhibit loyalty to particular formats?

2. What are the key determinants of cross-sectional differences in store mobility? How much variation is explained by the observable characteristics of the households, such as income and family size?

3. How do marketing activities such as aggregate price differences between stores influence shopper mobility?

4. How does innate mobility change with the duration a consumer shops in a store? Do consumers become more inertial with time, and if so, at what rate?

The answers to these questions are valuable to retail management. If most shoppers are not mobile, this has important implications for strategy - in particular the development of loyalty programs. If observable characteristics of consumers account for a large portion of the variation in mobility, retailers could tailor strategies to a select group of customers. If mobility is influenced by marketing initiatives such as price cuts, coupons, etc., this has implications for how to optimize resource allocation across the various components of the marketing mix. For example, escalation of marketing expenditures could be damaging because "cherry picking" may result in few short term retailer benefits, and more seriously, not be accompanied by any long term improvements in the size and stability of the customer franchise. 
We find evidence of substantial lack of mobility - almost three quarters of the customers are unlikely to change their main stores. This is quite remarkable given the presence of several competing stores within a small geographically contiguous area (shoppers are not constrained by distance or the lack of options). Second, for shoppers who transition, their behavior is not governed by observable demographics: demographic effects are not significant after unobserved consumer heterogeneity is controlled for. Thus, while demographic variables may account for category-level price sensititivies (e.g., Hoch et al, 1995) they do not appear to govern consumer mobility among stores. This result is surprising given that Bell et al (1998) show that demographic variables have a strong effect on store choice. We do, however, find a strong effect of the "shopping behavior profile" as average expenditure per trip and the frequency of shopping explain considerable cross-sectional variation. This is convergent with recent work which links shopping behavior variables to overall consumer price sensitivity (e.g., Ainslie and Rossi 1998; Bell and Lattin 1998; Manchanda et al 1999).

Third, relative product prices on particular shopping trips do not have a significant effect on transition probabilities. This does not imply that price-related variables per se are unimportant, but rather, that long term store selection is more likely made on the basis of aggregate price images (e.g., Alba et al 1994) instead of actual price differentials at specific instances in time. This finding points to an advantage of our focus on transitions from main stores - as opposed to trip-to-trip store choices - as the dependent measure in the study. While temporary price cuts induce store switching, they need not generate long term gains in the number of customers or levels of expenditure per customer. Fourth, the chance of store turnover decreases significantly with the duration at a store. This finding is consistent with the idea that it is more cost-effective to protect existing customers than to try to acquire outside customers. ${ }^{1}$ The paper is organized as follows. We provide some background and introduce the model and estimation approach in the next section. Section 3 describes the data and a descriptive analysis of the transition process. Section 4 reports the findings and section 5 concludes the paper.

\footnotetext{
${ }^{1}$ In the brand choice literature Rosenberg and Czepiel (1983) contend that attracting a new customer to a brand costs more than six times what is needed to keep an existing customer.
} 


\section{$2 \quad$ Background and Model}

\section{Related Work}

Our model is distinct from, but builds upon a number of previous studies. Early work on store choice processes utilized the negative binomial model (NBD) and the Dirichelet (e.g., Wrigley and Dunn 1984). These relatively parsimonious models do a surprisingly good job of capturing aggregate patterns in the data. Nevertheless, such approaches typically involve restrictive assumptions regarding the homogeneity of the store visit timing decisions and the way in which covariates can enter the model. In an effort to improve on these earlier approaches, Popkowski Leszczyc et al (1996) develop a competing risk hazard model to analyze the store visit timing decisions of households, while also recognizing that time to the next visit may depend upon the store currently selected. They find that the Gamma distribution provides the best characterization of the inter-visit timing process and account for several sources of observed heterogeneity among the households in their sample. In a further extension of this work, Popkowski Leszczyc et al (2000) incorporate a third shopper decision — the amount to spend — and also account for unobserved heterogeneity using a finite mixture approach.

A second stream of work looks more explicitly at the store choice decision (rather than the visit timing decision) of individual shoppers. Work in this area dates back to classic studies on location (e.g., Huff 1964), retail center attractiveness (e.g., Fotheringham 1988) through to more conventional panel data studies (e.g., Bell et al 1998). These approaches focus on store and shopper level characteristics and typically treat choice decisions as independent through time. A third important line of work deals with the behavior of store switching consumers. A number of authors have examined store sales data and tried to relate switching patterns to the marketing activities of stores (price and promotion in particular). Studies include those by Kumar and Leone (1988) and Hoch et al (1994). While the former study found

that consumers will switch stores in response to price promotions in a single category (in this case, diapers), the latter reports that most consumers appear relatively insensitive to 
increases or decreases in price. Moreover, Bucklin and Lattin (1992) find no evidence for direct effects of marketing activity on store choice (i.e., consumers to do not switch stores in response to price specials on a single category).

In this paper we build upon these various findings in the following ways. Like Popkowski Leszczyc et al $(1996,2000)$ we are concerned with the transition process from one store to another, however we are more concerned with the probability of transitioning within a specific period, than the time to transition per se. Our objective here is quite different: we want to understand the factors that influence the stability of the customer base at a particular oulet. Moreover, we are able to consider a class of store covariates that we not available to those authors. ${ }^{2}$ While most of the store switching literature (e.g., Bucklin and Lattin 1992; Kumar and Leone 1998; Popkowski Leszczyc 1997) deals with store switching at a particular point in time, we are interested in factors (i.e., shopper or store characteristics) that determine whether or not a particular shopper is inherently switchable over a longer term. It is one thing to conclude that price promotions lead consumers to move amongst stores for particular trips and quite another to conclude that they are capable of inducing long term shifts in customer affililation. This links our work to studies on consumer inertia that have appeared in the brand choice literature (e.g., Keane 1997; Seethuraman et al 1999).

In sum, the distinguishing features of our work are a focus on: (1) individual shopper (versus aggregate) behavior, (2) a rich set of covariates including both store and shopper characteristics, and (3) a unique modeling approach in which the decision to switch main store affiliation, rather than simply switch stores, is the dependent variable of interest. ${ }^{3}$

\footnotetext{
${ }^{2}$ There are also some methodological differences. Both studies account for observed heterogeneity through shopper covariates, however we account for unobserved heterogeneity in a Bayesian random effects model.

${ }^{3}$ As we discuss shortly, we link the discrete time hazard approach to mobility to a random utility formulation of the "utility of switching." This offers the advantage that the model can be estimated in a simple random utility framework, given the appropriate definition of the dependent variable.
} 


\section{Model}

Store selection is a repetitive process with most shoppers visiting a grocery store 1-2 times per week. The shopper's relationship with a store can be understood through an analysis of transitions across a series of consecutive discrete time intervals, and central to our analysis is the idea that at each time interval, the shopper has a main store. The main store will be defined as the store that receives the greatest allocation of consumer expenditures in the associated interval. ${ }^{4}$ Of interest is the shopper's decision to transition (or not) from the main store in the next shopping time interval as each unit of time represents an opportunity for the shopper to continue with the store selected previously as the main store, or to switch to an alternative.

While our approach is different to a per-trip store choice model in which one models store selection from a fixed competitive set, there are some similarities. The decision to transition away from a preferred store is akin to the concept of "disadoption" of the store and disadoption occurs when the shoppers reaches a certain threshold level of dissatisfaction with the main store. As shown by Allison (1982), there is a direct mathematical relationship between a random utility model of choice and a discrete time hazard model in which the decision maker decides to adopt a particular innovation. Our discrete time hazard formulation can also be viewed as a model of "rejection" as we uncover the factors that encourage shoppers to abandon their historically preferred environments (see also Van den Bulte and Lilien 2001).

For shoppers, there are real benefits to maintaining affinity with primarily one store, or at least a small set, including economic benefits from loyalty programs and cognitive effort benefits related to knowledge of the store layout, etc. (e.g., Tang et al 2001). Despite this, the shopper may reach a threshold for disadoption and be motivated to seek out a new main store. The shopper could be inherently variety-prone, or a substantial change in store features or policies could precipitate a switch. From a management point of view, it is

\footnotetext{
${ }^{4}$ We provide precise definitions of "main store" and "time interval" in Section 3. For the moment it suffices to consider these terms conceptually.
} 
important to know whether such tendencies are related to observable characteristics of the shopper, or explicit actions taken by the store. Moreover, the implicit cost of disadoption and switching away from a main store could increase with time spent at that store.

\section{Specification}

We now describe the model specification. In the next section we discuss specific covariates and the important constructs of main store and time window. The dependent variable in the model is an indicator function which captures the transition behavior of the shopper, defined with respect to the main store and time window. Consider the store transitions of a sample of shoppers $i=1, \ldots, I$ visiting a set of competing stores $s=1, \ldots, S$. These shoppers are assumed to have access to all stores and the potential to make active choices at each occasion. Let $s_{i, t}$ be the main store of shopper $i$ at week $t$. The dependent variable or transition index $y_{i, t}$ is defined as

$$
y_{i, t}=1\left(s_{i, t} \neq s_{i, t-1}\right)
$$

such that it takes the value 1 if the current main store is different from the previous main store. Conceptually, this occurs when the shopper's dissatisfaction with the current main store reaches a critical threshold. Using this interpretation of the transition index we can invoke the notion of random utility and define the probability of transitioning away from the main store. Specifically, we define $p_{i, t}=\operatorname{Pr}\left(y_{i, t}=1\right)$, and then using the standard normal link function, $\Phi$, relate the probability of turnover to observable and unobservable characteristics of the store-household pair at each time of transition

$$
p_{i, t}=\Phi\left(\alpha_{i}+q_{i, t}^{\prime} \gamma+m_{i, t}^{\prime} \beta_{i}\right)
$$

In equation $(2.2) \alpha_{i}$ represents the unobserved innate mobility of household $i$, and $q_{i, t}$ is a vector of time-invariant household demographic and shopping behavior variables as well as $k-1$ time-varying dummy variables for the identity of the current main store (where store 
$k$ is the base). ${ }^{5} m_{i, t}$ includes a measure of the distance between the consumer and the store, the price for a common basket of goods, and duration dummy variables. $\gamma$ and $\beta_{i}$ are the response parameters which are either assumed common or shopper-specific, depending on the model formulation to be estimated. To see the link between the discrete time hazard interpretation and the random utility approach let $z_{i, t}$ represent the relative utility of main switching stores. In this case we have

$$
z_{i, t}=\alpha_{i}+q_{i, t}^{\prime} \gamma+m_{i, t}^{\prime} \beta_{i}+\varepsilon_{i, t}
$$

where $\varepsilon_{i, t} \stackrel{\text { iid }}{\sim}$ normal $(0,1)$. The relationship with the transition index is clearly seen when we transform the probit model in equation (2.2) as

$$
y_{i, t}=1\left(z_{i, t}>0\right)
$$

Our model formulation has a very parsimonious structure. In addition, it links the discrete time hazard notion of transitions to an underlying utility model where the latent utility is the "utility of switching main stores" rather than the utility of a particular alternative per se. Thus, our model is well suited to understanding the long term evolution of a customer base as it relates to a specific store environment.

\section{Observed and Unobserved Heterogeneity}

It is well known that one must account for both observed and unobserved heterogeneity in models of this type (see Allenby and Rossi 1999 for a review). This is especially true in the store selection context given wide variation across households in frequency of shopping and expenditure levels. In order to fully explore the role of heterogeneity, we estimate four versions of the model. Model [1] represents the base case and we restrict the response parameters to be common across all shoppers in the sample. Model [2] allows for heterogeneity in intercept term $\alpha_{i} \sim N\left(a, \sigma_{\alpha}^{2}\right)$ while $\beta_{i}=\beta$ for all $i$. Because the shoppers differ only

\footnotetext{
${ }^{5}$ The store dummies change over time as customers move across stores. This is the reason that $q_{i, t}$ has a time index. More justification for the covariates will be given in the next section.
} 
in their innate mobility, this formulation approximates the so-called "mover-stayer" model in the job mobility literature (e.g., Farber 1994). ${ }^{6}$ Model [3] introduces heterogeneity into the slope parameters. Letting $\delta_{i}=\left(\alpha_{i}, \beta_{i}^{\prime}\right)^{\prime}$, and $x_{i, t}=\left(1, m_{i, t}^{\prime}\right)$, the latent variable can be reformulated as

$$
z_{i, t}=q_{i, t}^{\prime} \gamma+x_{i, t}^{\prime} \delta_{i}+\varepsilon_{i, t}
$$

with $\delta_{i} \sim N(\delta, \Sigma)$. Model [4] is motivated by recent work on the role of shopping behavior variables in choice behavior (e.g., Ainslie and Rossi 1998; Manchanda et al 1999). For each shopper we compute the average expenditure per trip and the average shopping frequency. We are then able to break down the differences in household-level response parameters $\left(\delta_{i}\right)$ using the finite segmentation based on these two variables. Using the sample medians as cut off points, we assign shoppers into four non-overlapping segments (see Table 1).

\section{[Table 1 about here]}

With $w_{i}$ as a vector of dummy variables representing the segment, we allow the mean of the random effect parameters to interact with the segmentation variables. That is, $\delta_{i} \sim N\left(w_{i}^{\prime} \bar{\delta}, \Sigma\right)$. This approach allows us to tie our analysis of heterogeneity in transition propensity to two variables that are readily observable by retail managers. It also opens up a way of linking our analysis of transitions to existing findings from the literature on store choice.

\section{Caveats and Estimation}

We assume that the probability of turnover is independent of the destination stores. More generally, one could work with a duration model in which each pair of origin and destination stores has its own hazard function (for a brand switching application see Vilcassim and Jain 1991). In order to conserve data for estimation we include only two duration variables (see

\footnotetext{
${ }^{6}$ Technically, a pure stayer is a shopper with $\alpha_{i}=-\infty$.
} 
next section for details) and as a consequence it is not possible to see the entire profile of the duration dependence. In theory, while an explicit hazard model with a flexible baseline hazard function could alleviate this problem our data argue in favor of our simple probit as an approximate discrete time hazard model with two states (main store and other stores). This is because $30 \%$ of the shoppers never change their main stores during the entire sample period.

We assume the heterogeneity distribution is normal. This is a popular assumption in the marketing literature (e.g., Allenby and Lenk 1994; Allenby and Rossi 1999), but can sometimes be restrictive. One alternative is to extend the model with a nonparametric approach to heterogeneity using a Dirichlet prior (see Escobar and West 1995; Hirano 2001). We estimated this model and the results are very similar to those based on the normal distribution. This is a likely due to having many observations per household. ${ }^{7}$

Model specification is completed by specifying the prior distribution of the parameters. To minimize the impact of the prior, we use either flat or weakly informative priors. ${ }^{8}$ Es- $^{-}$ timating the hierarchical (random effect) probit model is straightforward using the Gibbs sampling method (Gelfand and Smith 1990) and the detailed computational algorithm is well documented in the previous literature (e.g., Allenby and Rossi 1999, Rossi et al 1996). To assess convergence, we run 10 parallel Gibbs chains with different starting values (Gelman and Rubin 1992). We found that the Gelman-Rubin statistics the statistics for most parameters were very close to 1 after the first 5,000 iterations of each chain.

\section{$3 \quad$ Data and Preliminary Analysis}

We analyze inter-store transitions of 548 shoppers shopping over a two-year period (June 1991-June 1993), taking a total of 88,945 shopping trips at five local supermarkets. We

\footnotetext{
${ }^{7}$ Details of these results are available from the authors.

${ }^{8}$ Our results are not sensitive changes in priors. Again, this is due to the large sample size per shopper. The exact prior specification is available from the authors.
} 
observe shopper demographics, location relative to each store, and the merchandizing activity of the stores. Table 2 highlights differences in the number of trips received by stores and in their price formats. ${ }^{9}$

\section{[Table 2 about here]}

\section{Main Stores and Time Indices}

To define transitions it is first necessary to the establish a time interval over which main stores are defined, and then define the main store itself. In principle, we could define every change of shopping place (e.g., consecutive trips to two stores in a day) as a single transition, however, such a small window will blur the distinction between "major" shopping trips and some temporary "fill-in" trips (Kahn and Schmittlein 1989, 1992) in instances where customers cross-shop. Alternatively, if we set the time window too wide (e.g., one month), we would observe too few transitions per shopper (there are only two years of data, so we would have a maximum of 24 time windows per shopper). The selection of the duration window is at the discretion of the analyst, but must be established while keeping in mind the objective to create an appropriate definition of a "main" store.

The empirical distribution of trips across shoppers and within shoppers over time suggests that one week is an appropriate time window for our data. We do the following: for each of the 104 weeks we define the "main" grocery store of a shopper based on the total weekly expenditure (in dollars) at each of the five stores. ${ }^{10}$ In a given week, the main store of a shopper is the store where the shopper spent the most. From a customer management point of view, dollars spent is a meaningful measure for the retailer and it is striking that the

\footnotetext{
${ }^{9}$ These data come from the Stanford IRI Market Basket Database. The first two stores advertise an EDLP format, while the other three are HILO operators. Stores 1-3 are from different chains and stores 4-5 are from the same chain.

${ }^{10} \mathrm{~A}$ practical benefit of the one week window is that many grocery retailers alter marketing variables such as prices, store flyers and coupons on a weekly basis.
} 
main stores defined in this way account for approximately $94 \%$ of the total expenditure for all periods. The weekly average grocery expenditure per shopper is $\$ 40.25$, so that a typical household spends $\$ 37.71$ per week in their main grocery store and $\$ 2.54$ in secondary stores.

Table 3 summarizes the transition sample. If each of the 548 households has a shopping record in each of the 104 weeks, we would have 56,992 (548 × 104) main stores, however, some households have missing weeks so we instead have 43,612 transitions. The transition index, which is the dependent variable in our study, is constructed by comparing the main stores of a household for two consecutive weeks. It is set equal to 1 if the two stores are the same and 0 otherwise. In other words, the transition indices are defined over 43,064 (43,612 - 548) pairs of consecutive main stores. We use two duration covariates which requires us to set aside more data. 'Dur $1=1$ ' if the current store has survived for more than a week and 'Dur2=1' if the store has survived for more than two consecutive weeks. As such, we have to exclude the first two transition observations for each household ('Intitialization' in the table). We further divided the remaining sample of 41,968 transitions into a calibration sample of 40,872 transitions and a holdout sample of 1,096 transitions consisting of the last two observations for each household. ${ }^{11}$

\section{[Table 3 about here]}

In the calibration sample, the number of observations per shopper ranges between 34 and 101 (76.58 on average). The mean of the transition indicator in the calibration and holdout samples is 0.183 . On average, customers do not change their main stores very frequently, however there is wide variation in transition rates across the households. Figure 1 displays the histogram of transition rates by household. 162 households never change their main stores at all during the entire sample period, yet $17.1 \%$ households switch their main stores in more than $40 \%$ of the weeks.

\footnotetext{
${ }^{11}$ To ensure our results were robust, we also used various other splits of the data and report the results in the next section. The qualitative findings were unchanged and full results are available from the authors.
} 


\section{[Figure 1 about here]}

We examined whether the non-switching behavior of the 162 households is "forced" by geographical distance. For the non-switchers the average distance between current main stores and other stores is 2.17 miles and this is not significantly different from the average of 2.10 miles for the rest of the households. This implies non-switching observations result from conscious choice and are not dictated by distance to other stores.

Table 4 reports the sample transition matrix by origin and destination store and shows a clear stratification of the stores in terms of mobility. Customers are much more likely to turn over to stores of the same price format (e.g., 88.9\% of turnovers from store 1 (EDLP) were to store 2 (EDLP), and $87.3 \%$ turnovers from store 4 (HILO) were to store 3 (HILO)). Shoppers appear to be loyal not only to particular stores, but even when they do transition, they are loyal to particular formats.

[Table 4 about here]

\section{Selection of Model Covariates}

The selection of model covariates is motivated by our research questions and by previous research. Our covariates fall into two broad classes, namely variables that are householddependent and those that are transition-dependent. The first category includes both demographic and shopping behavior profiles, while the second captures store characteristics (tailored to individual shoppers). The selected variables serve a substantive purpose and also allow us to control for observed heterogeneity. ${ }^{12}$ Shopper-dependent covariates capture

\footnotetext{
${ }^{12}$ We also control for unobserved heterogeneity via random effects. To our knowledge this is the first study of transition behavior that has such a rich array of covariates and fully accounts for unobserved heterogeneity.
} 
the fact that the willingness to abandon a main store may be a consumer trait, whereas the transition-dependent covariates allow for the intervention of store-specific characteristics in a given time window. This allows the possibility that the willingness to transition is influenced by variables that change over time and describe the shopper's state. Table 5 lists each variable along with a full description of how it is operationalized and the reports the mean and standard deviation. ${ }^{13}$

The price variable represents the aggregate price advantage of one store over the others in a particular week, independent of the different shopping baskets of the households. Though somewhat restrictive in nature, this specification is in line with the previous research (e.g., Dickson and Sawyer 1990) that finds that customers rarely recall the price of a specific item when shopping, but can form impressions with respect to overall price image (e.g., Alba et al 1994). Table 5 shows there is significant variation in each of the covariates utilized in the study.

[Table 5 about here]

\section{Empirical Analysis}

We begin with model calibration and validation then proceed to interpret the marginal posterior parameter distributions. Because the models are nested in an increasing order of heterogeneity allowed for, it is straightforward to determine the marginal impact of each

\footnotetext{
${ }^{13}$ The distance variable is calculated from the shopper's home so we are not able to explicitly capture trips initiated from work. We have no reason to believe that trip initiation varies systematically across customers, so this should not introduce bias. Because only the difference will affect store selection, we subtract the average values of price and distance for all other stores from the variables for the current main stores (Fotheringham 1988). We also defined the variables relative to the best of those for the other stores, which is consistent with the notion of opportunity cost, however the results were similar to those reported here and we do not explore them further. Details are available from the authors.
} 
additional component by comparing the posterior estimates. All reported results (means and standard deviations) are based on the last 5,000 posterior draws from the Gibbs sampler whose convergence is verified by the first 5,000 "burn in" iterations using the GelmanRubin statistic ${ }^{14}$. The significance of a parameter in a Bayesian analysis should be based on the entire shape of the marginal posterior distribution, however, an illustrative significance measure is convenient for ease of exposition. Following Rossi et al (1996), we say that a parameter is significant if the posterior probability that the parameter has the same sign as the posterior mean exceeds 0.90 .

\section{Model Calibration and Validation}

We computed the log marginal density ${ }^{15}$ for each model using an approximated bootstrap method (Newton and Raftery 1994). It is clear from Table 6 that the fit of the model increases with the corresponding increase in level of heterogeneity. The magnitude of the improvement is substantial when one compares models [1] and [4], however there is a clear tapering off in the improvement of model [4] over model [3].

\section{[Table 6 about here]}

For "out-of-sample" fit, we predict the transitions of 1,096 holdout observations (2 per household) using the available posterior draws from the corresponding Gibbs sampler. Table 6 contains two different predictive measures. One is the average log predictive density, and the other the average percentage of correct predictions (i.e., the hit rate). Using either criterion, however, we see that the predictive performance significantly improves as we introduce heterogeneity in the intercept (model [2]) and also in response sensitivity (model [3]). Model [3] is able to predict $80 \%$ of the holdout transitions correctly. In contrast, the difference

\footnotetext{
${ }^{14}$ The statistics are omitted to save space

${ }^{15}$ The marginal density is the average likelihood integrated with respect to the prior density of the parameters. See Kass and Raftery (1995) for details.
} 
in predictive performance between models [3] and [4] was not particularly large. Though model [4] produced a superior log predictive density (-361.4 vs -365.1), there was less than a $1 \%$ gap in hit rate in favor of model [4] which employs the two-way segmentation of the households by expenditures and frequency.

One possibility here is that the disparity in predictive performance could be an artifact stemming from the small size of the holdout samples. To check this we reestimated the two models using almost equal sized calibration $(\mathrm{N}=21,109)$ and holdout $(\mathrm{N}=20,859)$ samples. In this case, model [4] maintains an edge in calibration sample fit $(-5,922.0$ versus $-5,933.7)$. The difference amounts to a Bayes factor (see Kass and Raftery 1995) of $1.2 \times 10^{5}$ in favor of model [4], if we assume the prior odds to be one. For holdout, model [3] had a slightly higher log predictive density than model [4] (-8, 052.2 versus -8, 054.8), and model [4] had a superior hit rate (0.798 versus 0.794$)$. Thus, we conclude that overall model [4] is marginally preferred over model [3].

\section{Substantive Findings}

Table 7 lists the parameter estimates and shows in boldface those that are significant based on the $90 \%$ posterior-band criteria. The model is specified such that the turnover probability increases with the covariate effect, so the table should be read as follows: "the main-store turnover probability is higher (lower) on average for the observations with a given characteristic, if the posterior mean of the associated parameter is positive (negative)." Differences in the level of heterogeneity accounted for by each of the four model specifications can be seen by looking across the four columns of Table 7 (we elaborate on this shortly).

[Table 7 about here] 


\section{The Effect of Demographics}

Demographic variables are an important source of observed heterogeneity. In Model [1] the store turnover probability is significantly higher for households subscribing to a newspaper $\left(\gamma_{4}=0.08\right)$, and having unemployed $\left(\gamma_{8}=0.10\right)$ or retired heads $\left(\gamma_{9}=0.07\right)$. This suggests that main store substitutions may be initiated by some new information (via promotion or advertising) on the relative merits of the alternative stores, and newspaper subscribers are more likely to be exposed to such information. Furthermore, the opportunity cost of gathering such information will be lower for retired, or non-working households.

Note, however that all effects of the demographic covariates disappear once unobserved heterogeneity is accounted for (see columns 3 and 4 in Table 7). This implies that retail managers are unlikely to be successful in preventing detections purely by using demographic targeting. It is of some comfort, however, to see that the main effects of shopping behavior variables generally remain strong even in the more flexible models.

\section{The Effect of Shopping Style}

Inter-store mobility decreases with average expenditure per trip $\left(\gamma_{10}<0\right)$ and increases with the average shopping frequency $\left(\gamma_{11}>0\right)$. Frequent shoppers are price-sensitive in brand choice (e.g., Ainslie and Rossi 1998) possibly due to better knowledge of price distribution acquired through experience. This same phenomenon could also drive them to transition main stores more often. Large-basket shoppers are less sensitive to category level price promotions in selecting stores (Bell and Lattin 1998) and their larger expenditures per trip may lead them to expend more effort to determine the "right" store and stay with it.

In all four models, the duration variables are highly significant. The longer a shopper stays with a main store, the more likely the shopper is to continue with that store. This effect is present even after accounting for both observed and unobserved heterogeneity. Further insight into the effect of inertia can be gained by looking at how the expenditure and 
frequency variables stratify the sample. The interactions for the random effects are shown under Model [4] in Table 8. In examining the table, recall that the segments are identified by expenditure level, and then by shopping frequency. For both duration variables the turnover probability is lower for the large basket shoppers (for the same frequency type). That is, the values of $\beta_{3 i}$ and $\beta_{4 i}$ are more negative for $(\mathrm{H}-\mathrm{H})$ in comparison to $(\mathrm{L}-\mathrm{H})$ and $(\mathrm{H}-\mathrm{L})$ in comparison to $(\mathrm{L}-\mathrm{L})$.

[Table 8 about here]

It is also interesting to see that the main effect of the frequency variable is no longer significant once the difference in inertia by the relative size of this variable is controlled for (see the estimate for $\gamma_{11}$ for Model [4] given in Table 7). In contrast, the cross-sectional difference by average expenditure remains significant in Model [4] $\left(\gamma_{10}=-0.52\right.$ in Table 7). In sum, large basket are less likely to transition away from their current main stores. This inertia effect is further reinforced when these large basket shoppers are also less frequent shoppers.

\section{The Effect of Distance and Store Characteristics}

The chance of customer turnover increases when a main store is more remote $\left(\beta_{1}>0\right.$ for models [1] to [3]). This is consistent with prior work that shows a more convenient location has a positive influence on store selection (Huff 1964). The inconvenient store could therefore be subject to "double jeopardy" — the remote location works against initial choice and also makes the store more vulnerable to defection. The interaction with segmentation by shopping style can be seen from the estimates of $\beta_{1 i}$ given in Table 8. Large basket shoppers, regardless of the shopping frequency, are less sensitive to the distance when deciding to transition from one main store to another $\left(\bar{\beta}_{1}=0.18\right.$ verus $\bar{\beta}_{1}=0.27$ for small basket shoppers). This result is intuitive for the following reason. The relative importance of a "fixed cost" such as 
distance traveled to the store decreases as the total expected cost of a shopping trip (travel time plus product expenditures) increases.

The absence of a basket price effect is worth noting. For both Model [1] and Model [2] $\beta_{2}$ is insignificant. In Model [3] the mean of the random effects, $\beta_{2 i}$, remains insignificant as do the interactions with the four shopping styles shown in the segmented analysis of Model [4] (see Table 8). These results are consistent with the notion that shoppers select main stores based on the relative price image reinforced by past experiences, rather than by a more frequent analysis of actual current price levels. That the null result for basket price persists in Model [4] suggests a modification of our previous claims regarding the shopping behavior variables — average expenditure and shopping frequency — on shopper mobility. Earlier, we attributed some of the effect of these variables on mobility to the fact that they have been shown to be strongly related to consumer price sensitivity (e.g., Kim and Rossi 1994; Manchanda et al 1999). That is, we simply argued that because less frequent shoppers are less price sensitive in brand choice, this means that one could expect them to also be less mobile. The fact that there is still no variation in the price effect across shopper types in Model [4] as shown by the mean values for $\beta_{2 i}$, suggests that some non-price elements could be contributing to the signifance of the expend and trip variables, shown by $\gamma_{10}$ and $\gamma_{11}$, respectively. While we do not have data to examine this, one could conjecture that a large basket shopper, almost by definition, also has a more favorable impression of store layout, service, assortment etc., all other things equal.

\section{Discussion and Conclusion}

Our research is motivated by the relative absence of work on customer mobility in retail settings. Most studies focus on transaction-specific choice behavior, rather than the long term transition process which is the focus of this research. As argued here, the notion of mobility is central to understanding customer allegiance and to the practice of customer management. It is just as important for retailers to understand the drivers of long term 
or stable customer behaviors, as it is to analyze the determinants of temporary switching behavior. We offer the following findings and implications for retail managers (particularly, but not exclusively, to those in grocery retailing or similar environments).

\section{Shopper Behavior}

1. Mobility. Supermarket shoppers are relatively immobile, even in the presence of several competing alternatives. It is important to realize that this finding is not directly comparable to or in conflict with previous findings that retail promotion has a positive effect on store substitution (e.g., Kumar and Leone 1988). While that effect is partly due to temporary cross-shopping, our result pertains to the transition of shoppers' main association — which is a much more stringent condition.

2. Observed Characteristics and Mobility. Once unobserved heterogeneity is controlled for, demographic characteristcs play no role in explaining main-store turnover. On the other hand, the observed "shopping style" of the consumer is highly predictive. Large basket shoppers and infrequent shoppers are considerably less likely to change their main-store allegiance. This finding complements and goes beyond existing work. While previous papers have tied these variables to price sensitivity and store selection (e.g., Ainslie and Rossi 1998; Bell and Lattin 1998; Manchanda et al 1999), we show that they also contribute to stickiness with the preferred store over a longer time horizon.

3. Distance, Price Levels and Mobility. Shoppers are more likely to change a main store if the store is less convenient, but the likelihood decreases for customers who buy large amounts per trip. These shoppers can ammortize the relative inconvenience against the accummulation of other benefits (e.g., lower product prices, preferred assortments, etc.). We speculated a "double jeopardy" effect for inconvenience. These stores are less likely to be selected initially and more likely to suffer defections. Temporary changes in price levels do not appear to have any real effect on mobility. While shoppers undoubtedly switch for some trips, these changes to do not induce any lasting transition 
from the favored or main store. This suggests that customers consider the aggregate price images of the stores (e.g., Alba et al, 1994) — perhaps in the initial selection of a main store - rather than search over prices at each trip and then select the main store on that basis.

4. Inertia. We find strong evidence for state dependence in store mobility. This result complements earlier work on brand choice (e.g., Keane 1997) and cross-category purchasing behavior (e.g., Seethuraman et al, 1999). The longer a shopper continues with the current main store, the less likely the shopper will transition away to another main store. Nearly three-quarters of our sample can be classified as "inertial" with respect to mobility among main stores. ${ }^{16}$ Combined with the first finding above, this leads to an interesting conclusion: most shoppers are highly inertial and become more so with time at the preferred store. This likely results from the benefits associated with consumers learning about a particular store over time (e.g., store layout, product assortment, etc.).

\section{Implications for Retail Management}

1. Prioritizing and Targeting of Shoppers. The relative absence of mobility and the increase in inertia with time suggest that retail management should prioritize customers in the following order: (1) existing loyal customers, (2) new entrants to the market, and (3) shoppers who are potentially switchable from competitors. Existing customers are by nature less mobile and the longer they are immobilized the more likely it is they will remain in this state. New entrants to the market may shop around initially, but will most likely settle into a "steady state" of immobility. The third group will be the most difficult to attract and may be the most expensive from a marketing resource

\footnotetext{
${ }^{16}$ Table 8 the shows that the variances of the heterogeneity distribution for the duration parameters are large, so it is not immediately clear how many households are inertial in their selection of main stores. To answer this question, we computed at every iteration of the Gibbs sampler, the percent of households whose duration parameters are both negative. From 5000 iterations, the mean was $72.3 \%$ implying that a nearly three quarters of the shoppers are inertial.
} 
point of view. It is striking that many retail management practices appear to implicitly focus on (3), given that our research highlights the inherent difficulty of acheiving any long-lasting gains with this group.

2. Shopper Identification and Metrics. Efforts to identify segments of customers based on shopping style will be more valuable than targeting on the basis of observed demographics. While such variables can appear to be important, all effects disappear once unobserved heterogeneity is accounted for. Given the strong effect of average basket size in limiting mobility, retailers should measure and try to increase it. This may be a more worthwhile goal than simply increasing store traffic. The latter goal could be accomplished by short term price promotions that have no long term positive effect on the customer franchise. An increase in the average basket size should engender long term benefits: cross-sectionally, there is a negative correlation between average weekly expenditure and the probability of transitioning away from the main store $(r=-0.21, p<0.01)$. It is interesting to speculate that basket size and inertia together create a "virtuous circle" for retailers: Large basket shoppers are the most stable and attractive customers, and once shoppers start buying larger baskets per trip, they become more inertial. ${ }^{17}$

3. Marketing Activity. Marketing activities center on longer term strategic issues (e.g., price format, positioning, location, assortment, etc.) and more variable short term tactics (price promotions, features, coupons, etc.). We find some evidence that the longer term strategic issues have more impact on customer mobility. Table 4 shows that shoppers who transition do so to stores of similar formats (even though stores of different formats may be more conveniently located). This suggests that the overall positioning of the store is critical to the ability to improve the customer franchise. A retailer wanting to actively target customers of a competitor should focus on a

\footnotetext{
${ }^{17}$ The overriding objective of increasing the average order size per customer and visit also suggests other important metrics. Retailers have long recognized that keeping a shopper in the store for longer periods of time increases the incidence of unplanned purchases. Store managers should actively try to increase the time spent by shoppers as they walk through the store and manage to this metric.
} 
competitor of the same basic price format. Store location has some role to play as more convenient stores see less mobility overall. While we have not studied it directly, the composition of the assortment is vital in solidifying long term affiliation (see Fitzimons 2000) and is no doubt linked to time spent in the store and average basket size variables that have a significant impact on mobility. Retail programs that build store loyalty through the development of category-specific loyalty may also be successful in this regard (see Drèze and Hoch 1998). Conversely, short term price and promotion changes appear to have no significant influence on the long term composition of the customer base. ${ }^{18}$

We began by noting that stores with less mobile customer bases are likely to be more successful over the long run. The less mobile the customer base, the more the retailer acts as a "local monopoly" with respect to the shopper franchise. A store with a more transient population of customers faces two disadvantages: (1) greater variability in the revenue stream, and (2) continual pressure to replenish the customer base. By linking the concepts of "random utility for switching" with a discrete time duration framework, we arrived at a relatively simple random-effects probit model with which to investigate the transition process. While parsimonious, the model also accounts for a considerable degree of observed and unobserved heterogeneity.

We document the relative lack of mobility and the presence of strong inertia, while also identifying some of the key drivers and moderating variables. The most important drivers relate to shopper traits as defined by the shopping style rather than strictly exogenous characteristics such as demographics. The good news for retail managers is that these "traits" can be subject to influence by marketing activity and can easily be monitored through simple metrics such as average basket size. We hope this effort stimulates further work on what retailers can do to limit mobility and improve the quality of the customer base.

\footnotetext{
${ }^{18}$ While these activities do not lead to main store transitions, we cannot rule out the hypothesis that such activities are important in keeping existing customers. We thank an anonymous reviewer for this insight.
} 


\section{References}

[1] Ainslie, A. And P. Rossi (1998), "Similarities in Choice Behavior Across Product Categories," Marketing Science, 17, 92-106

[2] Alba, J., S. Broniarczyk, T. Shimp And J. Urbany (1994), "The Influence of Prior Beliefs, Frequency Cues, and Magnitude Cues on Consumer Price Judgments," Journal of Consumer Research, 21, 219-35.

[3] Allenby, G. And P. Lenk (1994), "Modeling Household Purchase Behavior with Logistic Normal Regression," Journal of the American Statistical Association, 89, 12181231.

[4] Allison, P. (1982), "Discrete Time Methods for the Analysis of Event Histories," 6198, in Sociological Methodology 1982 S. Leinhardt (Editor), San Francisco CA: JosseyBass.

[5] — - AND P. Rossi (1999), "Marketing Models of Consumer Heterogeneity," Journal of Econometrics, 89, 57-78.

[6] Bell, D., T-H Ho, And C. TAng (1998), "Determining Where to Shop: Fixed and Variable Costs of Shopping," Journal of Marketing Research, 35, 352-369.

[7] — - AND J. LATTin (1998), "Shopping Behavior and Consumer Preference for Store Price Format: Why "Large Basket" Shoppers Prefer EDLP," Marketing Science, 17, $66-88$.

[8] Blumen, I., M. Kogen and P. McCarthy (1955), The Industrial Mobility of Labor as a Probability Process, Cornell University Press, Ithaca, NY.

[9] Bucklin, R. And J. Lattin (1992), "A Model of Product Category Competition Among Grocery Retailers," Journal of Retailing, 68, 271-293.

[10] Chib, S., And E. Greenberg (1996), "Markov Chain Monte Carlo Simulation Methods in Econometrics," Econometric Theory, 12, 409-431.

[11] Chintagunta, P. (1998), "Inertia and Variety Seeking in a Model of Brand-Purchase Timing," Marketing Science, 17, 253-271.

[12] Dickson, P. And A. SAwyer (1990), "The Price Knowledge and Search of Supermarket Shoppers," Journal of Marketing, 54, 42-53.

[13] DrÈze, X. And S. Hoch (1998) " Exploiting the Installed Base Using CrossMerchandising and Category Destination Programs," International Journal of Research in Marketing, 15, 459-471.

[14] Escobar, M. And M. West (1995), "Bayesian Density Estimation and Inference using Mixtures," Journal of the American Statistical Association, 90, 577-588.

[15] Farber, H. (1994), "The Analysis of Interfirm Worker Mobility," Journal of Labor Economics, 12, 554-593.

[16] Fitzsimons G. (2000), "Consumer Response to Stockouts," Journal of Consumer Research, 27, 249-266. 
[17] Fotheringham, A. (1988), "Consumer Store Choice and Choice Set Definition," Marketing Science, 7, 288-310.

[18] Gelman, A., And D. Rubin (1992), "Inference from Iterative Simulation Using Multiple Sequences," Statistical Science, 7, 457-511.

[19] Gonul, F., And K. SRinivasan (1993), "Consumer Purchase Behavior in a Frequently Bought Product Category: Estimation Issues and Managerial Insights from a Hazard Function Model with Heterogeneity," Journal of the American Statistical Association, 88, 1219-1227.

[20] Hirano, K. (2001), "Semiparametric Bayesian Inference in Autoregressive Panel Data Models," Econometrica (forthcoming).

[21] Hoch, S., X. Drèze And M. Purk (1994), "EDLP, Hi-Lo, and Margin Arithmetic," Journal of Marketing, 58, 16-27.

[22] — - B-D Kim, A. Montgomery And P. Rossi (1995) "Determinants of StoreLevel Price Elasticity," Journal of Marketing Research 32, 17-29.

[23] Huff, D. (1964), "Redefining and Estimating a Trading Area," Journal of Marketing, $28,34-38$.

[24] Kahn, B. And D. Schmittlein (1989), "Shopping Trip Behavior: An Empirical Investigation," Marketing Letters, 1, 55-69.

[25] — _ AND —_ (1992), "The Relationship between Purchases Made on Promotion and Shopping Trip Behavior," Journal of Retailing, 68, 294-315.

[26] Kass, R. And A. RAftery (1995), "Bayes Factors," Journal of the American Statistical Association, 90, 773-795.

[27] Keane, M., (1997) "Modeling Heterogeneity and State Dependence in Consumer Choice Behavior," Factors," Journal of Business and Economic Statistics, 15, 31027.

[28] Kim, B-D., And P. Rossi (1994), "Purchase Frequency, Sample Selection, and Price Sensitivity: The Heavy User Bias," Marketing Letters, 5, 57-68.

[29] Kumar, V. And R. Leone (1988), "Measuring the Effect of Retail Store Promotions on Brand and Store Substitution," Journal of Marketing Research, 25, 178-186.

[30] Lal, R. And R. Rao (1997), "Supermarket Competition: The Case of Every Day Low Pricing," Marketing Science, 16, 60-80.

[31] Manchanda, P., A. Ansari A and S. Gupta (1999), "The 'Shopping Basket': A Model for Multicategory Purchase Incidence Decisions," Marketing Science, 18, 95-115.

[32] Newton, M And A. Raftery (1994), "Approximate Bayesian Inference with the Weighted Likelihood Bootstrap," Journal of the Royal Statistical Society, Ser. B., 56, $3-48$.

[33] Popkowski Leszczyc, P. And H. Timmermans (1996) "An Unconditional Competing Risk Hazard Model of Consumer Store-Choice Dynamics," Environment and Planning A, 28, 357-68. 
[34] — _ AND —_ (1997) "Store-Switching Behavior," Marketing Letters, 8, 193-204.

[35] — - A. Sinha And H. Timmermans (2000) "Consumer Store Choice Dynamics: An Analysis of the Competitive Market Structure for Grocery Stores," Journal of Retailing, 76, 323-45.

[36] Rosenberg, L. And J. Czepiel (1983), "A Marketing Approach to Customer Retention," Journal of Consumer Marketing, 2, 45-51.

[37] Rossi, P., R. McCulloch and G. Allenby (1996), "The Value of Purchase History Data in Target Marketing," Marketing Science, 15, 321-340.

[38] Seethuraman, P., A. Ainslie and P. Chintagunta (1999), "Investigating Household State Dependence Effects Across Categories," Journal of Marketing Research, 36, 488-500.

[39] Tang, C., D. Bell And T-H Ho (2001), "Store Choice and Shopping Behavior: How Price Format Works," California Management Review, 43, 56-74.

[40] Trivedi, M., F. Bass And R. Rao (1994), "A Model of Stochastic Variety Seeking," Marketing Science, 13, 274-297.

[41] Van den Bulte, C. And G. Lilien (2001), "Two-Stage Partial Observability Models of Innovation Adoption," Working paper, Wharton School of Business.

[42] Vilcassim, N. And D. Jain (1991), "Modeling Purchase-Timing and Brand-Switching Behavior Incorporating Explanatory Variables and Unobserved Heterogeneity," Journal of Marketing Research, 28, 29-41.

[43] Wrigley, N. And R. Dunn (1984), "Stochastic Panel-Data Models of Urban Shopping Behaviour: 2. Multistore Purchasing Patterns and the Dirichelet Model," Environment and Planning A, 16, 759-778. 


\begin{tabular}{cccc}
\hline \hline Segment & Weekly expenditure & Weekly shopping trip & \% of households \\
\hline H-H & High & High & $23 \%$ \\
H-L & High & Low & $27 \%$ \\
L-H & Low & High & $26 \%$ \\
L-L & Low & Low & $24 \%$ \\
\hline Cut-off (median) & 32.45 dollars & 1.259 trips & H=548 \\
\hline
\end{tabular}

Table 1: Segmentation of Customers.

\begin{tabular}{cccc}
\hline \hline Store I.D. & Trip Frequency (\%) & Mean Basket Price (S.D.) & Advertising Pricing Format \\
\hline 1 & $15933(17.9)$ & $22.22(1.05)$ & EDLP \\
2 & $19346(21.8)$ & $22.61(1.26)$ & EDLP \\
3 & $31706(35.6)$ & $25.78(1.57)$ & HILO \\
4 & $12318(13.8)$ & $27.94(2.34)$ & HILO \\
5 & $9642(10.8)$ & $27.72(2.35)$ & HILO \\
\hline
\end{tabular}

Note: For consistency with prior literature, we replicate the basket prices computed by Bell et al (1998, p 357).

Table 2: Frequency of Trips $(\mathrm{N}=88,945)$ and Pricing Format by Store.

\begin{tabular}{llr}
\hline \hline Sample & Description & Observation \\
\hline Total weekly main store & 104 week $\times 548$ hhd & 56,992 \\
Main store not defined & incidence of no weekly purchase & $-13,380$ \\
& & $=43,612$ \\
\hline Transition & Pairs of 2-consecutive-week main stores & $=43,064$ \\
Initialization & First 2 weeks per hhd for duration dummies & $-1,096$ \\
Hold-out & Last 2 weeks per hhd for out-of-sample prediction & $-1,096$ \\
Calibration & & $=40,872$ \\
\hline
\end{tabular}

Table 3: Sample Selection Procedure 


\begin{tabular}{crrrrr|r}
\hline \hline & \multicolumn{7}{c}{ Destination store } \\
\cline { 2 - 7 } Origin store & 1 & 2 & 3 & 4 & 5 & Total \\
\hline 1 (EDLP) & 6,821 & 1,318 & 82 & 7 & 75 & 8,303 \\
2 (EDLP) & 1,313 & 9,652 & 405 & 95 & 195 & 11,660 \\
3 (HILO) & 78 & 405 & 11,109 & 1,171 & 434 & 13,197 \\
4 (HILO) & 8 & 84 & 1,176 & 3,199 & 78 & 4,545 \\
5 (HILO) & 84 & 188 & 418 & 87 & 3,486 & 4263 \\
\hline Total & 8,304 & 11,647 & 13,190 & 4,559 & 4,268 & 41,968 \\
\hline
\end{tabular}

Table 4: Store Transition Observations 


\begin{tabular}{|c|c|c|}
\hline Covariate & Description & Mean (S.D.) \\
\hline \multicolumn{3}{|c|}{ Household-dependent } \\
\hline FamSize & The number of family members in a household. & $2.32(1.38)$ \\
\hline Income & $\begin{array}{l}\text { Log of annual household income. The variable was imputed as the } \\
\text { mid-point of the bracket which each household belongs to. }\end{array}$ & $10.2(0.92)$ \\
\hline White & 1 if the main household head is white. & 0.73 \\
\hline News & 1 if the household subscribes to at least one newspaper. & 0.36 \\
\hline Old & $\begin{array}{l}1 \text { if at least one household head is older than } 55 \text {. The age variable } \\
\text { is originally grouped by } 6 \text { categories. }\end{array}$ & 0.55 \\
\hline College & 1 if at least one household head has a college equivalent degree. & 0.44 \\
\hline Single & 1 if male or female household head is absent. & 0.49 \\
\hline Unemp & 1 if no household head is working. & 0.38 \\
\hline Retire & 1 if the main household head has retired. & 0.32 \\
\hline Expend & $\begin{array}{l}\text { Log of average weekly shopping expenditure }(\$) \text { at all stores during } \\
\text { the entire sample period. }\end{array}$ & $3.57(0.45)$ \\
\hline Trip & $\begin{array}{l}\text { Log of average weekly shopping trips at all stores during the entire } \\
\text { sample period. }\end{array}$ & $0.27(0.57)$ \\
\hline \multicolumn{3}{|c|}{ Transition-dependent } \\
\hline Distance & $\begin{array}{l}\text { The relative distance to the current main store differenced by the } \\
\text { average distance to the other stores. }\end{array}$ & $-1.37(1.55)$ \\
\hline Price & $\begin{array}{l}\text { The relative price of a fixed shopping basket at the current main } \\
\text { store differenced by the average price at all other stores for the week } \\
\text { of transition. }\end{array}$ & $-0.75(3.11)$ \\
\hline Dur1 & $\begin{array}{l}1 \text { if the current store has retained the main store status for more } \\
\text { than } 1 \text { previous week. }\end{array}$ & 0.82 \\
\hline Dur2 & $\begin{array}{l}1 \text { if the current store has retained the main store status for more } \\
\text { than } 2 \text { previous weeks in a row. }\end{array}$ & 0.73 \\
\hline
\end{tabular}

Table 5: Variable Description (548 households and 40,872 transitions). 


\begin{tabular}{lcccc}
\hline & \multicolumn{4}{c}{ Model } \\
\cline { 2 - 5 } Performance Criteria & {$[1]$} & {$[2]$} & {$[3]$} & {$[4]$} \\
\hline For calibration sample $(\mathrm{N}=40,872)$ & & & & \\
$\quad$ Log Marginal Density & $-14,999$ & $-13,067$ & $-11,950$ & $-11,937$ \\
For hold-out sample $(\mathrm{N}=1,096)$ & & & & \\
$\quad$ Log Predictive Density & -420.0 & -386.4 & -365.1 & -361.4 \\
Hit Rate & 0.769 & 0.784 & 0.800 & 0.809 \\
\hline
\end{tabular}

Table 6: Comparison of Model Performance 


\begin{tabular}{|c|c|c|c|c|}
\hline Parameter & Model 1 & Model 2 & Model 3 & Model 4 \\
\hline \multicolumn{5}{|c|}{ Demographics } \\
\hline Intercept $(\alpha)$ & $0.603(.046)$ & random effect & r.e. & r.e. with segments \\
\hline FamSize $\left(\gamma_{1}\right)$ & $\mathbf{0 . 0 3 8}(.009)$ & $0.110(.041)$ & $0.010(.046)$ & $0.029(.038)$ \\
\hline Income $\left(\gamma_{2}\right)$ & $\mathbf{0 . 0 4 4}(.012)$ & $0.161(.035)$ & $0.039(.038)$ & $0.068(.053)$ \\
\hline White $\left(\gamma_{3}\right)$ & $0.010(.021)$ & $0.061(.076)$ & $0.121(.092)$ & $0.148(.104)$ \\
\hline News $\left(\gamma_{4}\right)$ & $0.082(.018)$ & $0.062(.083)$ & $0.039(.105)$ & $0.024(.093)$ \\
\hline $\operatorname{Old}\left(\gamma_{5}\right)$ & $\mathbf{- 0 . 0 5 0}(.023)$ & $-0.033(.102)$ & $-0.032(.098)$ & $-0.032(.111)$ \\
\hline College $\left(\gamma_{6}\right)$ & $0.034(.019)$ & $0.050(.098)$ & $0.113(.100)$ & $0.128(.082)$ \\
\hline Single $\left(\gamma_{7}\right)$ & $-0.019(.022)$ & $-0.048(.103)$ & $-0.073(.106)$ & $-0.015(.108)$ \\
\hline Unemp $\left(\gamma_{8}\right)$ & $0.105(.028)$ & $\mathbf{0 . 2 8 0}(.126)$ & $0.147(.129)$ & $0.155(.119)$ \\
\hline Retire $\left(\gamma_{9}\right)$ & $\mathbf{0 . 0 7 2}(.027)$ & $0.035(.126)$ & $0.034(.150)$ & $0.019(.120)$ \\
\hline \multicolumn{5}{|c|}{ Shopping behavior } \\
\hline Expend $\left(\gamma_{10}\right)$ & $\mathbf{- 0 . 3 3 0}(.023)$ & $\mathbf{- 0 . 7 2 7}(.095)$ & $\mathbf{- 0 . 4 9 0}(.094)$ & $-0.518(.125)$ \\
\hline $\operatorname{Trip}\left(\gamma_{11}\right)$ & $0.248(.016)$ & $0.542(.070)$ & $0.305(.080)$ & $0.135(.138)$ \\
\hline \multicolumn{5}{|c|}{$\underline{\text { Store dummies }}$} \\
\hline Store $2\left(\gamma_{12}\right)$ & $\mathbf{- 0 . 0 8 6}(.005)$ & $\mathbf{- 0 . 1 4 4}(.033)$ & $-0.094(.084)$ & $-0.090(.080)$ \\
\hline Store $3\left(\gamma_{13}\right)$ & $\mathbf{- 0 . 1 6 6}(.035)$ & $\mathbf{- 0 . 1 8 7}(.056)$ & $\mathbf{- 0 . 3 6 2}(.133)$ & $\mathbf{- 0 . 3 4 7}(.132)$ \\
\hline Store $4\left(\gamma_{14}\right)$ & $0.141(.048)$ & $0.299(.069)$ & $0.274(.138)$ & $0.305(.133)$ \\
\hline Store $5\left(\gamma_{15}\right)$ & $-0.088(.050)$ & $-0.030(.071)$ & $-0.060(.118)$ & $-0.088(.134)$ \\
\hline \multicolumn{5}{|c|}{ Other variables } \\
\hline Distance $\left(\beta_{1}\right)$ & $0.068(.005)$ & $0.075(.008)$ & r.e & r.e. with segments \\
\hline Price $\left(\beta_{2}\right)$ & $-0.002(.005)$ & $0.001(.005)$ & r.e. & r.e. with segments \\
\hline $\operatorname{Dur1}\left(\beta_{3}\right)$ & $\mathbf{- 0 . 4 1 1}(.026)$ & $\mathbf{- 0 . 3 9 3}(.026)$ & r.e. & r.e. with segments \\
\hline $\operatorname{Dur2}\left(\beta_{4}\right)$ & $\mathbf{- 0 . 9 9 8}(.024)$ & $\mathbf{- 0 . 4 0 5}(.026)$ & r.e. & r.e. with segments \\
\hline
\end{tabular}

Table 7: Gibbs Sampling Results with Different Levels of Consumer Heterogeneity 


\begin{tabular}{|c|c|c|c|c|c|}
\hline Parameter & \multicolumn{4}{|c|}{ Mean $(\bar{\alpha}, \bar{\beta})$} & Variance $(\operatorname{diag}(\Sigma))$ \\
\hline Intercept $\left(\alpha_{i}\right)$ & \multicolumn{4}{|c|}{ Model [2] } & $0.73(.07)$ \\
\hline & \multicolumn{4}{|c|}{ Model [3] } & \\
\hline Intercept $\left(\alpha_{i}\right)$ & \multicolumn{4}{|c|}{$1.042(.08)$} & $0.47(.08)$ \\
\hline Distance $\left(\beta_{1 i}\right)$ & \multicolumn{4}{|c|}{$\mathbf{0 . 2 2 9}(.03)$} & $0.26(.03)$ \\
\hline Price $\left(\beta_{2 i}\right)$ & \multicolumn{4}{|c|}{$0.014(.01)$} & $0.04(.01)$ \\
\hline $\operatorname{Dur1}\left(\beta_{3 i}\right)$ & \multicolumn{4}{|c|}{$\mathbf{- 0 . 5 0 9}(.05)$} & $0.23(.03)$ \\
\hline $\operatorname{Dur2}\left(\beta_{4 i}\right)$ & \multicolumn{4}{|c|}{$\mathbf{- 0 . 3 7 4}(.05)$} & $0.27(.04)$ \\
\hline & \multicolumn{4}{|c|}{ Model [4] } & \\
\hline Segment & $(\mathrm{H}-\mathrm{H})$ & $(\mathrm{H}-\mathrm{L})$ & $(\mathrm{L}-\mathrm{H})$ & $(\mathrm{L}-\mathrm{L})$ & \\
\hline Intercept $\left(\alpha_{i}\right)$ & $0.98(.34)$ & $\mathbf{0 . 7 0}(.38)$ & $\mathbf{0 . 8 3}(.35)$ & $\mathbf{0 . 7 6}(.38)$ & $0.44(.07)$ \\
\hline Distance $\left(\beta_{1 i}\right)$ & $\mathbf{0 . 1 8}(.06)$ & $\mathbf{0 . 1 8}(.07)$ & $0.27(.06)$ & $\mathbf{0 . 2 6}(.07)$ & $0.25(.03)$ \\
\hline Price $\left(\beta_{2 i}\right)$ & $-0.02(.02)$ & $0.03(.03)$ & $0.02(.02)$ & $0.02(.03)$ & $0.05(.01)$ \\
\hline $\operatorname{Dur1}\left(\beta_{3 i}\right)$ & $\mathbf{- 0 . 4 9}(.08)$ & $\mathbf{- 0 . 7 4}(.12)$ & $\mathbf{- 0 . 3 8}(.07)$ & $\mathbf{- 0 . 5 8}(.10)$ & $0.24(.03)$ \\
\hline $\operatorname{Dur2}\left(\beta_{4 i}\right)$ & $\mathbf{- 0 . 3 0}(.08)$ & $\mathbf{- 0 . 6 8}(.11)$ & $\mathbf{- 0 . 2 4}(.07)$ & $\mathbf{- 0 . 4 6}(.10)$ & $0.28(.03)$ \\
\hline
\end{tabular}

Table 8: Distribution of Random Effect Heterogeneity 
Figure 1: Distribution of Transition Rates Across Households

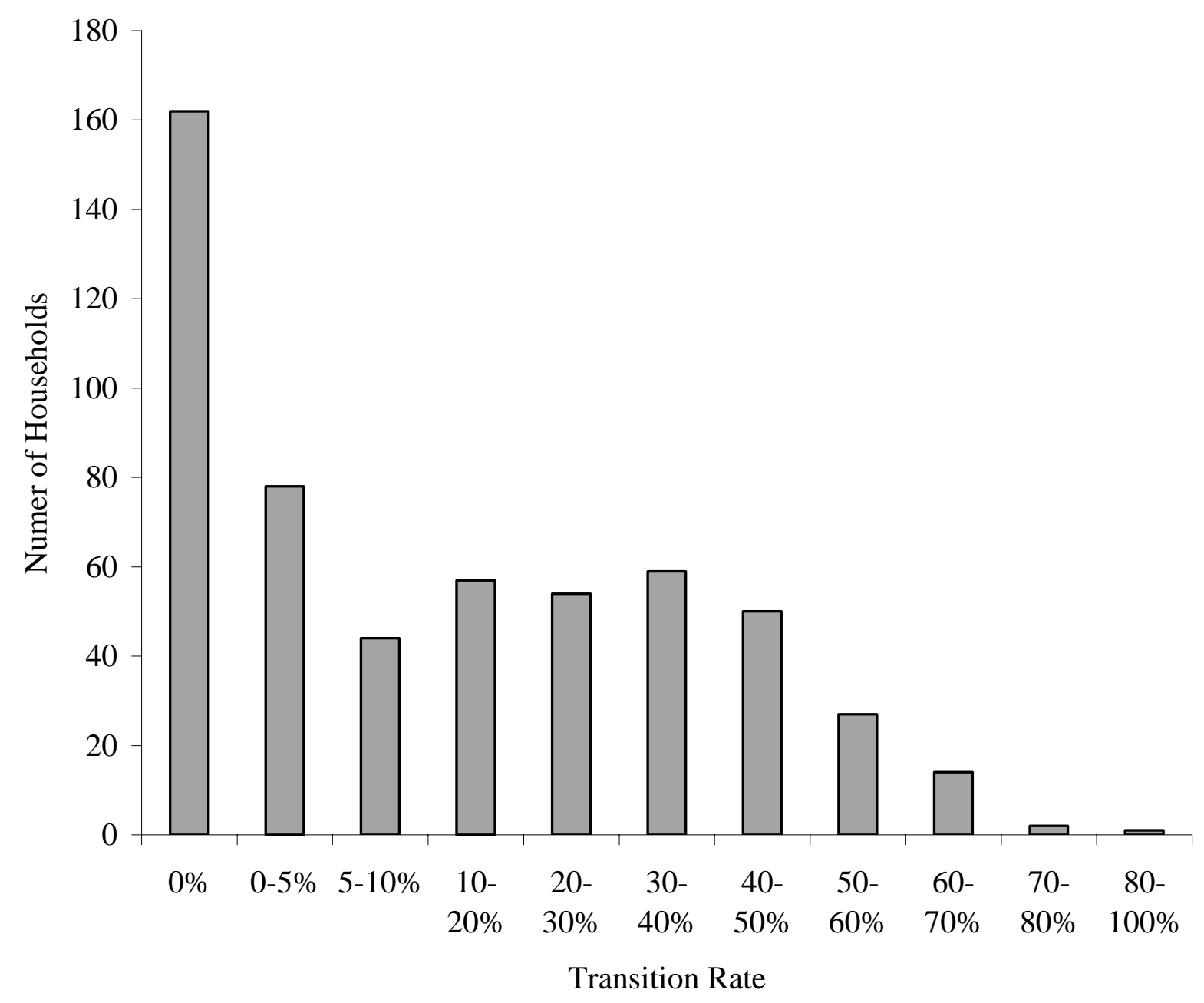

